\title{
FUNÇÃO MATERNA, EDUCAÇÃO E ATO EDUCATIVO*
}

\author{
THE MATERNAL FUNCTION, EDUCATION AND THE EDUCATIONAL ACT
}

Thelma Pontes Borges, da Universidade Federal do Tocantins.

\begin{abstract}
RESUMO
O presente texto tem como objetivo discutir como a função materna é condição para o surgimento de um sujeito psíquico instaurado no simbólico, considerando que, por tal função, é possível transformar um corpo biológico em humano, a partir das inscrições simbólicas dadas pelo Outro. Situamos a educação como resultado dessas inscrições simbólicas que possibilitam a transmissão de um sentimento de filiação, necessário ao advento do sujeito. Ao se considerar a função materna como fundante da educação, discutimos também como o ato educativo é por nós compreendido como estruturado justamente a partir das experiências primordiais, sem as quais nossa existência ficaria comprometida. Dessa forma, este texto pretende demonstrar como a educação é resultado da função materna e como o ato educativo é um derivado de tal função.
\end{abstract}

Palavras-chave: Função materna. Ato educativo. Psique. Psicanálise.

\section{INTRODUÇÃO}

O presente texto tem como objetivo discutir como a função materna é condição sine qua non para o surgimento de um sujeito psíquico instaurado no simbólico, considerando que por meio de tal função é possível transformar um corpo biológico em humano a partir das inscrições simbólicas dadas pelo Outro. Além disso, situamos a educação como resultado destas inscrições simbólicas, que possibilitam a transmissão de um sentimento de filiação necessário ao advento do sujeito. Educação que é resultado de uma violência (KUPFER, 1998) que se faz inevitável e estruturante da psique humana. Ao se considerar a função materna como fundante da educação, discutimos também como o ato educativo, apesar de ser muitas das vezes compreendido como a ação que desenvolve habilidades e competências e oferece formação, é por nós compreendido como estruturado justamente a partir das experiências primordiais, sem as quais nossa existência ficaria comprometida. Desta forma, nosso texto pretende demonstrar como a educação é resultado da função materna e como o ato educativo é um derivado de tal função.

Com base na teoria psicanalítica, temos a considerar que só existe educação se houver alguém que se inscreva na vida do bebê como representante da função materna. $\mathrm{E}$ que, por meio de tal função imponha ao corpo do infans uma ordem de regulação em termos de ritmos, movimentos e manifestações que produzam interpretações desse corpo. Kupfer (1998, p.130) escreve: "essa atribuição de sentidos, acompanhada da suposição de

\footnotetext{
* Artigo recebido em 29/06/2009 e aprovado em 25/09/2009
} 
que ali já está um sujeito, é a responsável pelo recorte e pela moldagem, sobre aquele pedaço de carne, de um sujeito."

Quando um bebê nasce, seu organismo biológico é colocado dentro de um funcionamento emocional-social que faz com que se desdobre às regras relacionais e se regule pelas normas educativas de cada família. Assim, o sono, a alimentação e até as fezes e a urina passam a guiar-se pelos ditames familiares e será o encontro entre esse organismo com tais condições que fará com que o infans adquira um corpo e comece a esboçar um sujeito psíquico (BERNARDINO, 2006). O processo educativo que os pais cumprem em relação a seus filhos - banho, amamentação, sono - gera uma mensagem às crianças para que estas se ajustem e correspondam aos ideais de filho demandados pelos pais. Dessa forma, toda organização constitutiva da criança será dada pelo desejo do Outro (JERUSALINSKY, 1999).

Para Kupfer (2000), a principal educação ocorre nesse processo estrutural do ser humano, podendo a escola, inclusive, herdar as funções parentais (MARTINS, 2001). É a educação materna, com as suas prerrogativas, a saber, função materna e função paterna, que possibilita, de fato, as educações subseqüientes. Assim, aprendizagem, socialização, conhecimento e outras atribuições dadas à infância são consequiências dessa primeira educação oferecida no seio familiar. Podemos expor, com segurança, que os aspectos de desenvolvimento a serem conquistados pela criança, sejam eles neurológicos, psicomotores, emocionais, sociais ou cognitivos, dependem de um elemento organizador - o aspecto psíquico.

É sabido que este aspecto psíquico inicia sua formação nas primeiras interações da mãe com o feto e com o bebê (SÁ, 2001). Esses elementos psíquicos são garantidos e sustentados pela figura materna, que antecipa no bebê características que ainda não lhes são peculiares. Em outras palavras, a mãe fala, sente e interpreta pelo bebê (AULAGNIER, 1979), oferecendo um lugar na família e uma inscrição na linguagem, do qual resultará um sujeito desejante. Só poderemos falar de escolarização se antes houver uma educação materna que tenha oferecido um psiquismo. Como afirma Bernardino (2006, p.37) essa criança precisa estar "submetida a um processo de inscrição no campo simbólico que lhe permita ser sujeito de sua história, ou seja, falar em nome próprio."

A possibilidade de contato com o outro é que oferecerá as inscrições psíquicas necessárias a esse processo. É na relação, submetida à função materna que o bebê constituirá uma "imagem corporal", estabelecida pela escritura dos desejos maternos. Freud (1980) escreve que o corpo da criança se constrói na relação com o outro que cuida dele. Talvez, até, um dos grandes méritos de Freud tenha sido oferecer-nos essa noção de corpo imaginário que se distingue do corpo real. É a compreensão de que o registro psíquico ocorre deste encontro mágico entre "mãe e filho", no qual a criança torna-se "sua majestade o bebê".

Bernardino (2006, p.30) expõe:

o bebê possui reflexos que só funcionam quando encontram alguém para dar sentido - direção, significado, sensibilidade - a eles. Portanto, pode-se perceber aí a dimensão do lugar que ele vai dar a este que vai humanizá-lo: um Outro primordial que, com suas palavras, seu olhar e seus toques marca-o com o seu desejo, sua imagem. 
É neste encontro entre mãe e bebê, que acontece logo após o nascimento, que surge, ou não, um lugar subjetivo, um berço psíquico no qual o bebê poderá enfrentar as situações desconfortantes e se organizar. Podemos levantar a hipótese de que deste encontro surgem duas direções: a primeira é que a mãe, frente ao desamparo físico e emocional do bebê, se reorganize oferecendo os elementos necessários à sua constituição. Na segunda, a mãe fica destituída de seu lugar, em prol de cuidados de puericultura e médicos, fixando a criança no real e não possibilitando a ascensão ao registro imaginário.

Seja qual for a direção tomada na relação, o futuro deste ser humano será marcado pelo desempenho ou fracasso da função materna, o que determinará seu desenvolvimento global e sua adequação sócio-educacional.

\section{FUNÇÃO MATERNA E TRANSMISSÃO SIMBÓLICA}

A formação do ser humano enquanto sujeito desejante, ocorre a partir da transformação da maternagem em transmissão psíquica, via interpretação dos atos reflexos do bebê. Tal interpretação oferece à mãe e à criança a crença de que ali existe um ser cognoscível.

O nascimento de um filho é para os genitores sempre foco de inúmeros desejos e fantasias. Mesmo antes do nascimento do filho, o casal parental ou os envolvidos no processo veem-se frente a uma série de construções sobre o ser que está por chegar. A cada roupa adquirida ou objetos comprados, uma torrente enorme delas aparece quanto às características, aos modos e aos jeitos que o bebê terá. Será moreno? Terá cabelos encaracolados? Vai ser médico? Um bebê nunca nasce desprovido desse berço psíquico, mesmo que tal berço não seja tão aconchegante quanto deveria.

Quando um bebê nasce, pai e mãe precisam conhecer esse novo ser e encontrar-se com ele. $\mathrm{O}$ bebê sonhado e desejado não é exatamente o mesmo que nasceu. Esse ser real precisa ser apresentado ao casal parental e esses devem adotá-lo emocionalmente. Nem sempre esse encontro produz frutos de amor imediato; há a necessidade de se conhecerem e, para tanto, de um tempo para falarem a mesma linguagem. Tal processo pode acontecer em poucas horas, alguns dias, meses, anos ou nunca, podendo trazer repercussões infinitas para todos (BERNARDINO, 2006).

Para que um sujeito nasça psiquicamente, não é suficiente que tenha todas as suas necessidades atendidas; é preciso que exista um Outro primordial que tenha prazer com essa satisfação. As primeiras marcas psíquicas são dadas justamente a partir do investimento emocional da mãe no cuidar de seu filho e na instalação do mamanhês, que se configura como a fala infantilizada da mãe, que acredita traduzir para o bebê e para ela mesma o que este está sentindo. É o estabelecimento de uma relação ímpar entre mãe e filho, que envolve trocas de olhares que compreendem, confortam, traduzidos na fala da mãe com o bebê. Segundo Laznik (2006, p.98) "o mamanhês é o dialeto de todas as mães do mundo quando elas falam com seus bebês: a voz é postada um tom mais alto e a entonação é exagerada."

As funções parentais lançam o bebê para uma história e para um desejo que modificam suas funções orgânicas, ampliando-as. A mãe é enlaçada pela criança por se sentir atraída por ela e toma os reflexos como sendo dirigidos a ela. Como exemplo, a mãe 
entende que o sorrir (reflexo) é uma resposta de agrado a seu contato e, por isso, mais amor e atenção são oferecidos ao bebê, que, por sua vez, passa a responder cada vez mais até que o ato reflexo de sorrir se transforme no ato voluntário de sorrir.

Para que serviria a um bebê recém- nascido ter um reflexo que imita um andar ou subir escadas? Senão para, como disse uma colega, 'enganar a mãe', e a partir desse engano possibilitar um vínculo com a matriz simbólica, que fará com que estes reflexos desapareçam para retornar após alguns meses não mais como uma possibilidade de dar passos, mas como uma conquista deste bebê, que agora já pode decidir por quais caminhos já quer andar. (SANSON, 2006, p.62).

A mãe é absorvida por uma ilusão de que seu bebê é especial e que tem comportamentos que respondem à sua demanda e ao seu desejo, passando a investir cada vez mais na relação com seu filho. $O$ desenvolvimento dessa relação levará a mãe a aproximar-se da criança emocionalmente pelo mamanhês e a desenvolver a capacidade de interpretar as reações e comportamentos do recém-nascido (AULAGNIER, 1979). Nesse momento, é como se a mãe se emprestasse psiquicamente ao bebê, dando sentido à sua existência e significado às suas sensações. Assim, frio, fome, cólicas, medo, manha, passam a ser designados e saem da lógica do sem-sentido.

$\mathrm{O}$ ato da mãe de interpretar o bebê possibilita o aparecimento de um eu desvinculado do da mãe. Após este processo, ocorre a entrada de um terceiro na relação, que encerra de fato a relação simbiótica entre mãe e filho instaurando um sujeito submetido à linguagem e ao desejo.

Algumas condições são necessárias para que esse processo de separação ocorra a contento: primeiro, para que ocorra um investimento libidinal, é necessário que a mãe tenha um amor dedicado a seu filho; depois, é necessário que a própria mãe tenha sofrido o recalque de sua sexualidade infantil, pois só assim ela conseguirá oferecer um discurso estruturado e marcado pelo simbólico para a criança; além disso, é preciso que consiga exercer sua função para o aparecimento de um $e u$ da criança. E, por fim, resta ainda a estruturação de um sujeito desejante, que só aparecerá se houver a referência a um pai, na medida em que ele é o representante dos outros. É a referência a este outro que colocará o sujeito na ordem do cultural (BORGES, 2006). Entendemos pai como

[...] uma quantidade de trabalho psíquico exigido do pai (ou de um terceiro) no contato com o bebê [...] não só no investimento libidinal, mas também na limitação da loucura materna, sustentando assim uma distância entre a mãe e o bebê, necessária ao surgimento do sujeito psíquico (ROCHA, 1997, 15)

Esta última condição conhecida como Metáfora paterna ou Nome do Pai, será apresentada pela mãe. Cabe a ela sustentar a função do pai frente ao filho e permitir que este se desvincule e tenha condições de caminhar pelas próprias pernas. A metáfora paterna traz em si toda a discussão acerca do Édipo, castração e identificações, permitindo concluir como ocorre a formação da psique humana e como esta se estrutura em termos neuróticos, sujeitando-se às leis da castração, ou não. 


\section{EDUCAÇÃO É EDUCAÇÃO PRIMORDIAL}

Normalmente, pensamos no debate sobre educação quando nos reportamos às questões da instituição escolar; contudo, entre o nascimento de uma criança no hospital (primeira instituição educativa) até a entrada na escola, passa-se um tempo demasiadamente longo e definitivo em termos de constituição psíquica e cristalização dos problemas apresentados (JERUSALINSKY, 2002).

A infância torna-se objeto direto da educação quando se cria sobre a criança um olhar particularizado, que a vê como portadora de características que devem ser preservadas (ARIẼS, 1981), e, mais do que isso, como a via de realização e a promessa de imortalidade do adulto. Com a aura que representa a criança, esta se torna importante em termos de investimentos sociais e emocionais e os cuidados com ela passam a ser função da mãe, por conta da história social da família e da criança.

A mãe, mediante a sua função, deve criar a criança e provê-la de tudo que é necessário ao seu desenvolvimento. Para a realização do alimentar, do limpar, do acalentar, dentre outras atividades que deve realizar com presteza, a mãe é eleita a guardiã do bebê. Ao mesmo tempo que se elege a mãe a responsável, temos um hall de especialistas dizendo o que deve ou não ser feito. Afinal, as crianças são o futuro da humanidade e não podem ficar relegadas à particularidade; desse modo, a parentalidade torna-se um dever público, "cabendo ao Estado o bem-estar, a segurança e a proteção das crianças." (KAMERS, 2004, p.40)

E o que era da ordem privada da parentalidade passa a sofrer a intervenção do Estado. Como se cuida ou não de um bebê é agora ser regido por especialistas. As creches são bons exemplos para se pensar isto. No entanto, se por um lado vemos uma preocupação com a educação antes da escola formal, por outro, devemos pensar que educar não é limpar ou alimentar (no caso dos bebês), ou transmitir conteúdos (no caso das crianças), educar é inscrever marcas de desejo, é humanizar o outro pelo encontro sublime e pela transmissão psíquica entre dois seres, o que é impossível de acontecer pela intervenção pública, pois é algo da particularidade.

A maternagem - que é da ordem do universal, isto é, qualquer pessoa tem condições de cuidar de um bebê, pois puericultura se encontra em manuais - não é sinônimo de função materna (KAMERS, 2004). Se a maternagem é universal, a função materna é da ordem do singular. Somente ocorrem inscrições primordiais se os cuidados de alimentação e higiene forem particularizados por quem exerce a maternagem. A função materna singulariza o bebê, a mãe e a relação, inscrevendo o infans num lugar específico de seu desejo. É por conta dessa especificidade da relação que a mãe consegue supor demandas do bebê e interpretá-las, integrando as sensações neurofisiológicas do bebê no campo do dizível, da linguagem, do puramente humano. O bebê deixa de ter desconfortos fisiológicos e passa a ter fome, sede, cólica, manha; suas reações são interpretadas, nomeadas e humanizadas. Essas inscrições primordiais são a educação.

Assim, para que a função materna produza uma inscrição significante, é necessário que haja uma particularização dos cuidados na relação do outro com a criança. O que implica uma diferença radical entre isso que é da ordem de um 
universal - a maternagem - e aquilo que é da ordem do singular - a função materna." (KAMERS, 2004, p.43)

Os cuidados que a mãe dedica ao bebê não são fundamentais simplesmente porque proveem suas necessidades fisiológicas, e sim, porque são únicos, insubstituíveis e intransferíveis. A relação que a mãe desenvolve com seu bebê oferece existência simbólica, condição para a introdução à linguagem e constituição psíquica.

Por maternagem ser diferente de função materna, não estamos lidando com algo que possa ser prescritivo. Ou seja, não podemos dizer a alguém como exercer a função materna; apenas podemos auxiliá-la a cuidar de uma criança. A função materna foge completamente das vias conscientes de exercício; a maternagem, por outro lado, passa justamente por essa via. Assim, maternagem refere-se a cuidados conscientes e função materna está para muito além disso.

Por considerar as inscrições primordiais sinônimo de educação, temos que pensar também que os hospitais, onde nascem os bebês, são de fato a primeira instituição educativa, uma vez que ele pode, através de procedimentos institucionais, facilitar ou dificultar o encontro da mãe com o infans. A humanização no parto, a diminuição de cesarianas, a participação da família nas salas de parto, o alojamento coletivo entre mãe e bebê, são alguns dos fatores que podem ser pensados como favorecedores deste encontro e promotores da educação.

Falta ainda a educação, de um modo geral, perceber que educar é da ordem da humanização e ocorre no encontro entre um Outro primordial e a criança. A educação pode servir como mais um elemento na constituição do universo psíquico do bebê e das crianças, oferecendo, não prescrições, mas condições específicas de funcionamento que garantam a especificidade nas relações entre os cuidadores/professores (maternagem) e as crianças para que estes singularizem suas práticas (função materna).

\section{Ato EDUCATIVO? FunÇÕES PARENTAIS?}

$\mathrm{O}$ ato educativo envolve sempre alguém em busca de conhecimentos em contato com outro alguém que, supostamente, tem condições de fornecer tais conhecimentos. Está diretamente relacionado a pressupostos criados sócio-historicamente e determinados pelas normas sociais de aquisição de novas formas de saber (PAIN, 1985). O ato educativo é objeto de reflexão de professores de diversas áreas, que tentam elucidar que instrumentos são, ou não, mais interessantes e viáveis ao ato de aprender. E tem como principal objetivo promover a educação em todas as suas instâncias e funções.

Segundo Freud (1980), em Mal estar na civilização, a humanidade teve que escolher entre a pulsão e a civilização e até, o momento, a civilização está ganhando, uma vez que mantemos nossas pulsões nos trilhos pela égide da educação (PAIN, 1985) e utilizamos nossa energia para bens culturais. Assim, a educação é responsável não só pela humanização, como também pela socialização e constituição dos bens culturais da humanidade. Não podemos desvincular o trabalho educativo da formação humana e da manutenção da humanidade. 
Desta forma, entendemos que a função materna é um paradigma do ato educativo e que, a cada conhecimento transmitido pelo professor, ele está atribuindo significados e interpretando o que surge, tal qual a pessoa no exercício da função materna. Podemos inclusive colocar como correlatas a função educativa e a função materna (VOLICH, 2008), uma vez que ambas são estruturadas pelas experiências primordiais do ser humano, em momentos específicos de grande desamparo do inicio da vida que foram superados pelas inscrições dadas pelo Outro.

As inscrições oferecidas pelo ato educativo historicizam o homem e o colocam numa rede social, filiando-o a uma cultura. $\mathrm{O}$ ato educativo deve estar filiado a esse passado do homem (sua ligação com a função materna) para que opere com eficácia a transmissão de conteúdos passados. "Entre o passado e o futuro, o ato educativo se sustenta nos ideais sociais simbólicos articulados numa ética de humanização, socialização e subjetivação que ele próprio elabora." (ANDREOZZI, 2007, p.1).

$\mathrm{O}$ ato educativo pauta-se pela função materna como condição para que o educador tenha laços identificatórios, para que seu discurso se sustente. O esvaziamento da educação como ato simbólico exclui a ética das relações, gerando violência. $\mathrm{O}$ excesso de instrumentalização da pedagogia torna o ato educativo puramente técnico, desprovido de subjetividade, e sem conexão do sujeito com o Outro. Ou seja, o passado é retirado do processo educativo, e como não existe transmissão sem passado, o ato educativo não se produz nem produz o futuro. $\mathrm{E}$ a Educação se apresenta fraturada naquilo que a constitui, a formação humana.

$\mathrm{O}$ ato educativo deve ser configurado como tecido elementar básico que opera na organização psíquica do ser humano, inscrevendo-o na linguagem. Quando os pais educam o filho especificamente no exercício da função materna, transmite-se um discurso articulado que se constitui no próprio ato de educar. A educação "é um processo sociocultural e se define por uma intervenção social" (ANDREOZZI, 2007), o ato educativo constitui-se como tal e implica na inscrição de um significante na cadeia simbólica do sujeito.

$\mathrm{O}$ advento do sujeito e a inscrição na linguagem possibilitam ao ser humano sobreviver às intempéries do desamparo do começo da vida e o contato com o conhecimento, visto que a linguagem oferece o conhecimento e que a mãe fornece os significantes necessários à diminuição do fisiológico e à crescente entrada no cultural. A mãe não oferece simplesmente o alimento para suprir uma necessidade orgânica; ela oferece juntos todo o significado e o desejo ao amamentar seu filho. Transmite saber. A mãe possui um suposto saber, é ela que diz o que o outro sente, pensa e tem, possibilitando à criança instalar-se como gente. Educação é um ato de fazer laços sociais, articulando um significante ao outro na cadeia de significantes.

É o próprio exercício da função materna que lança a criança ao encontro da função paterna. É o discurso estruturado da mãe que apresenta a hiância, a falta, permitindo a operação do terceiro na relação. Diminui a unidade mãe-filho, mas permitindo que este terceiro seja responsável pela inscrição desejante e abertura de novos laços sociais.

Pensando em ato educativo como funções parentais, temos, então, que os discursos contidos na educação, nos mitos e na ciência expressam um modo de viver e são resultados de suposto saber, tal qual o suposto saber da mãe sobre o filho. "O que a educação pode transmitir são discursos de suposto saber, por ser ela também, um ato de discurso, 
submetida ao significante...” (ANDREOZZI, 2007, p.8). A educação atua pela palavra, e tenta se sustentar inscrevendo-se no sujeito.

Temos que considerar então, que ao professor é oferecido um poder único e singular: quando o desejo de saber do aluno se aferra ao suposto saber do mestre, pelas vias dialéticas da transferência. O professor sai da maternagem e ganha o status de mestre (função materna/paterna). As transformações do professor em mestre assim como a passagem da maternagem à função materna fogem das vias conscientes, e perpassam por caminhos tortuosos. A transmissão de conhecimento pelo mestre não se reduz a conhecimento, é existencial. "O lugar de mestre, para este professor, é da ordem de uma marca pessoal, um nome, possibilitando então a transmissão" (GUTIERRA, 2003, p.85). E, ao mesmo tempo em que este mestre se apresenta com seu amor na relação para a transmissão ele/deve assumir e sustentar também a lei, a cultura, ou seja, manter algo da ordem da função paterna.

Para tanto, o professor/mestre deve apresentar-se como um sujeito em falta, sem tamponar o desejo pelo saber, para que o desejo de saber do aluno possa circular (FERNANDÉZ, 1991). O ato educativo deve sustentar a lei (função paterna), a história (função materna). além de veicular um "deve ser" (nada é certo, somos seres faltantes), que é o reconhecimento da castração. Isto diz de um mestre que abre mão de seu narcisismo e se reconhece como não completo, podendo, assim, não ter horror ao ato educativo por este denunciar sua falta e sua história.

\section{Abstract}

This text sets out to discuss how the maternal function is a condition for the appearance of a psychic subject founded on the symbolic, considering that through such a function a biological body can be transformed into a human one starting from the symbolic registrations given by the Other. We have placed education as the result of these symbolic registrations, which make possible the transmission of a necessary feeling of filiation, vital for the advent of the subject. When considering the maternal function as foundational for education, we also discussed how the educational act is understood as having been structured exactly from primordial experiences, without which our existence would be compromised. In this way our text sets out to demonstrate how education is the result of the maternal function and how the educational act is a derivation of such a function.

Key-words: Maternal function. Educational act. Psyche. Psychoanalysis.

\section{REFERÊNCIAS}

ANDREOZZI, M. L. Educação: inscrição simbólica do desejo. In: Educação $e$ Subjetividade. Publicação do grupo de pesquisa Educação e Subjetividade da PUCSP/CNPQ. Disponível em: www.educacaoesubjetividade.com.br, 2007.

ÁRIES, P. História social da criança e da família. Rio de Janeiro: LTC, 1981. 
AULAGNIER, P. A violência da interpretação: do pictograma ao enunciado. Rio de Janeiro: Imago, 1979.

BERNARDINO, L. M. F. A abordagem psicanalítica do desenvolvimento infantil e suas vicissitudes. In: $O$ que a Psicanálise pode ensinar sobre a criança, sujeito em constituição. São Paulo: Escuta, 2006.

BORGES, T. P. Considerações sobre o autismo infantil. In: Mental: revista de saúde mental e subjetividade da UNIPAC. v. 4, n.7 ,nov. 2006. Barbacena: UNIPAC, 2003.

FERNADÉZ, A. A inteligência aprisionada. Porto Alegre: Artes Médicas, 1991.

FREUD, S. [1905] Três ensaios sobre a teoria da sexualidade. Obras Psicológicas Completas. Rio de Janeiro: Imago, 1980, v. VII.

. [1930]. O mal - estar na civilização. Obras Psicológicas Completas. Rio de Janeiro: Imago, 1980, v. XXI

GUTIERRA, B. C. C. Adolescência, psicanálise e educação: o mestre "possível" de adolescentes. São Paulo: Avercamp, 2003.

JERUSALINSKY, A. Psicanálise e desenvolvimento infantil. Porto Alegre: Artes \& Ofícios, 1999.

JERUSALINSKY, J. Enquanto o futuro não vem: a psicanálise na clínica interdisciplinar com bebês. Salvador: Ágalma, 2002.

KAMERS, M. Do universal da maternagem ao singular da função materna: reflexões acerca da educação primordial. In: Pulsional Revista de Psicanálise. São Paulo, vol. 180, 2004.

KUPFER, M. C. Violência da educação ou educação violenta? In: LEVISKY, D. L. Adolescência pelos caminhos da violência. São Paulo: Casa do Psicólogo, 1998.

Educação para o futuro. Psicanálise e educação. São Paulo: Escuta, 2000.

LAZNIK, M. C.. Interações sonoras entre bebês que se tornaram autistas e seus pais. In: $O$ que a Psicanálise pode ensinar sobre a criança, sujeito em constituição. São Paulo: Escuta, 2006.

MARTINS, V. A. C. Espaço escolar como herdeiro das funções parentais. Estilos da Clinica. Revista sobre a infância com problemas. São Paulo: USP-IP, v.VI, n11, 2001. 
PAIN, S. Diagnóstico e tratamento dos problemas de aprendizagem. Porto Alegre: Artmed, 1985.

ROCHA, P. S. A função paterna revisada pela clínica do autismo. In: O espaço e tempo na Psicanálise. Revista Pulsional, Centro de Psicanálise, São Paulo, ano X, n.102, out. 1997.

SÁ, E. Psicologia do feto e do bebé. Lisboa: Fim de século, 2001.

SANSON, J. C. Mais uma vez, as inscrições primordiais. In: O que a Psicanálise pode ensinar sobre a criança, sujeito em constituição. São Paulo: Escuta, 2006.

VOLICH, R. M. Da ação terapêutica ao ato educativo. In: Estados Gerais da Psicanálise Grupo Virtuais e Textos em Interlocução na rede. Disponível em: www.estadosgenerales.org/gruposvirtuais/volich, acesso em 06/07/2008.

Thelma Pontes Borges é professora de Psicologia do curso de História da Universidade Federal do Tocantins. Graduada em Psicologia pela Unesp/Assis e mestre em educação pela Unicamp. 